\title{
Needs of Siblings of Persons with Psychosis: A Systematic Descriptive Review
}

\author{
Anekal C. Amaresha, ${ }^{1,2,3}$, Ganesan Venkatasubramanian ${ }^{2,3}$, D. Muralidhar ${ }^{1}$ \\ 'Department of Psychiatric Social Work, National Institute of Mental Health and Neurosciences, ${ }^{2}$ The Schizophrenia Clinic, Department \\ of Psychiatry, National Institute of Mental Health and Neurosciences, ${ }^{3}$ Translational Psychiatry Laboratory, Neurobiology Research Centre, \\ National Institute of Mental Health and Neurosciences, Bangalore, India
}

\begin{abstract}
Research on caregivers of psychosis has predominantly focused on parents and spouses. Issues related to siblings of persons with psychosis (SOPP) are yet to be evaluated comprehensively. Like parents and spouses, SOPP also share the caregiver burden and have their own issues and needs. This systematic descriptive review aims to identify the types of needs of SOPP in the published literature and gives implications for further practice and research. The primary data search was carried out with predefined protocol in PubMed database and an additional hand search was done in EBSCOhost, ProQuest, Scopus, and PsychINFO. All the searches yielded a total of 862 titles. After screening for necessary inclusion criteria, seven studies were included in the final review. The results are discussed under six major themes that emerged from this review. Six out of seven studies highlighted the need for information on siblings' illness and participation in caregiver support group. Other important needs were illness management or rehabilitation needs; help in managing their own psychosocial issues; treatment related informational needs; and inclusion in treatment process. The socio-demographic details of these studies showed that majority of the participants were female siblings of Caucasian or white British ethnicity and from developed countries. SOPP predominantly have specific needs such as informational and support group needs, which are different in the priority of other primary caregiver needs. Paucity of literature from developing countries and the limitations of the existing studies warrant further systematic research.
\end{abstract}

KEY WORDS: Psychosocial needs; Siblings; Psychosis.

\section{INTRODUCTION}

Social dysfunction or deterioration, which can interfere in continuing an employment and independent living in the community, is a major feature of psychosis like schizophrenia and related disorders. ${ }^{1-4)}$ The psychosocial intervention adjunct to pharmacotherapy will help in maintaining medication compliance and reducing schizophrenia symptoms. ${ }^{5}$ However, the dysfunction caused by the negative symptoms significantly affects the social support of persons suffering from psychosis. ${ }^{6,7)}$ Hence, the family support plays a critical role in the recovery of illness ${ }^{8)}$ and this forms a major support system for persons with " psychosis. $^{9)}$

Research has shown that social support among persons

Received: February 17, 2014 / Revised: March 25, 2014

Accepted: April 7, 2014

Address for correspondence: Anekal C. Amaresha, MSW, MPhil Department of Psychiatric Social Work, First Floor, Dr. M.V.

Govinda Swamy Centre, National Institute of Mental Health and

Neurosciences, Bangalore-560029, Karnataka, India

Tel: +91-80-26995366, Fax: +91-80-26564830

E-mail: amarmsw@gmail.com suffering from psychosis is minimal, and primarily consists of immediate family members as compared with the general population. ${ }^{10)}$ Consequently, the primary caregivers have to carry the substantial part of caregiving tasks. Families with minimal social support networks require more support in these tasks. Hence, siblings of persons with psychosis (SOPP) can provide additional social support for their affected siblings.

The empirical literature shows that primary caregivers such as parents and spouses were well researched regarding their psychosocial issues. However, it was noted that in the absence of other primary caregivers, they play an important role in caring for their affected sibling. ${ }^{11,12)}$ In this context, it is important to note that many psychosocial intervention studies with caregivers of psychosis have shown that the number of siblings who participated in the interventions are less compared to the parent and spouse caregivers. $^{13-22)}$

SOPP are also negatively affected and share the burden of the illness. ${ }^{23-27)}$ It is important to formulate the targeted psychosocial interventions to alleviate their specific prob-

() This is an Open-Access article distributed under the terms of the Creative Commons Attribution Non-Commercial License (http://creativecommons.org/licenses/by-nc/3.0) which permits unrestricted non-commercial use, distribution, and reproduction in any medium, provided the original work is properly cited. 
lems and address their specific needs, which might enhance the support system for the affected sibling in the long run. In a limited way, the earlier reviews highlighted the role and importance of siblings in the treatment of psychosis; ${ }^{28)}$ the historical overview and developments of research on siblings, ${ }^{29)}$ and impact of illness on siblings and parents. $^{30)}$ However, they did not highlight the types of psychosocial needs of SOPP that could help us understanding and providing services to this population. Also by reviewing the literature on psychosocial needs of SOPP will help us to understand the limitations in the current studies that are necessary to guide further practice and research with this population. With this background, we aimed to systematically review studies, which have explored the psychosocial needs of SOPP.

\section{MATERIALS AND METHODS}

The main aim of this systematic review is to identify the psychosocial needs of SOPP in the published literature. The needs were operationalized as informational needs on illness such as symptoms, causes, treatment etc.; help in managing own emotions and psychosocial issues; help in crisis in terms managing illness behaviours; help in rehabilitation and recovery; support group needs; any other needs reported by the SOPP in the published literature. The review was carried out based on a predefined protocol.

\section{Selection Criteria}

We selected and reviewed studies based on the predefined inclusion and exclusion criteria, as given below: Inclusion criteria:

1. Studies, which have focused mainly on psychosocial needs of SOPP or schizophrenia or first episode psychosis or severe mental illness and other studies, which have addressed the psychosocial needs as one of the variable.

2. Studies published from January 1992 to October 2013.

3. Full text articles in English language.

Exclusion criteria:

1. Narrative reviews

2. Research protocols

3. Conference abstracts or proceedings

4. Studies other than needs of SOPP

\section{Search Strategy}

The primary electronic data search was carried out in PubMed database and hand search was carried out in
EBSCOhost, ProQuest, Scopus, and PsychINFO during the months of September and October 2013. The data search was completed on 30th October 2013. The search was performed in PubMed using the combination of four groups of search terms, which were predefined, by using PubMed Advanced Search Builder. To get relevant titles and abstracts, the truncation (*) symbol was added to the most basic word and phrases were quoted to get all the associated terms, which were included in the search. The field of search was restricted to titles and abstracts of publications, using “tiab" PubMed search tag.

\section{Search Terms}

The exact combination of four search terms used were:

1. Sibling* [tiab] OR brother* [tiab] OR sister* [tiab] OR "first degree relative" [tiab] OR "first-degree relative" [tiab] OR "first degree relatives" [tiab] OR "first-degree relatives" [tiab] OR caregiver* [tiab] OR carer* [tiab]

2. Schizophrenia [tiab] OR schizophrenic [tiab] OR psychosis [tiab] OR psychotic [tiab] OR "severe mental illness" [tiab] OR "severe mental disorder" [tiab] OR "severe psychiatric disorder" [tiab]

3. Need* [tiab] OR concern* [tiab] OR demand* [tiab] OR want* [tiab]

4. Emotion* [tiab] OR psychological [tiab] OR social [tiab] OR psychosocial [tiab] OR psycho-social [tiab] OR service [tiab] OR counseling [tiab] OR education* [tiab] OR psychoeducation* [tiab] OR information* [tiab] OR treatment [tiab] OR management [tiab] OR training [tiab] OR welfare [tiab] OR individual [tiab] OR family [tiab] OR parent* [tiab] OR marital [tiab] OR financial [tiab] OR recreation* [tiab] OR respite [tiab] OR emergency [tiab] OR crisis [tiab] OR support* [tiab]

\section{Study Selection}

Only studies on SOPP where their psychosocial needs were assessed, as one of the variables was included in this review. Altogether a total of 862 titles for screening were received and 126 of them were removed due to duplication. The remaining 736 titles and abstracts were screened for eligibility. Six hundred eighty-five studies were excluded for not meeting the selection criteria (Fig. 1). This stage of the selection process resulted in 51 studies on psychosocial issues of SOPP, which were further screened for studies on psychosocial needs of SOPP. In the final stage, 44 studies were excluded and other seven full text articles were included for this systematic descriptive 


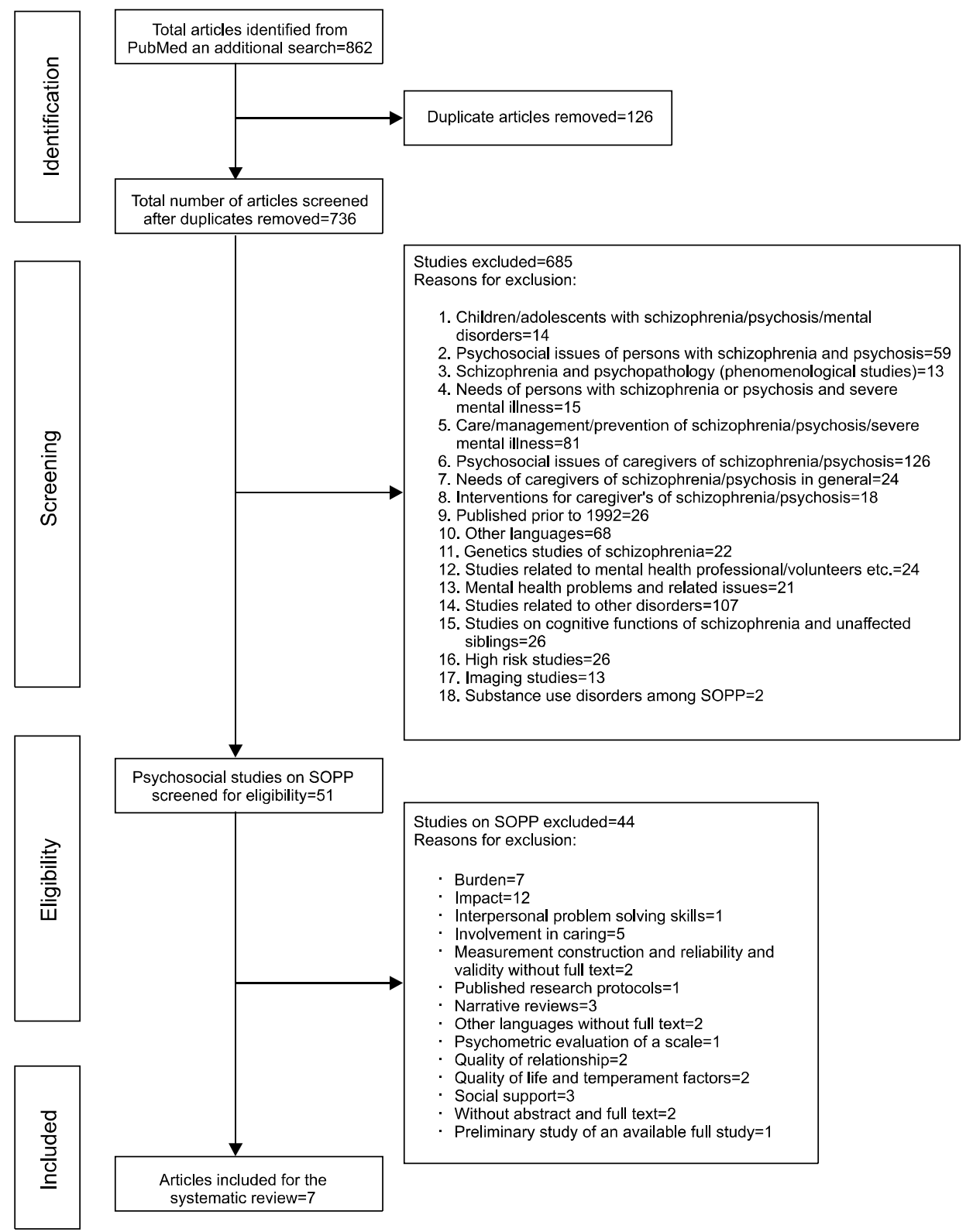

Fig. 1. Flow chart of selection process. SOPP, siblings of persons with psychosis.

review. Among the seven included studies, some of them had also focused on variables other than psychosocial needs of SOPP. However, the findings of those variables were not presented and discussed in this review since the focus was primarily on the psychosocial needs of SOPP.

\section{Data Extraction and Analysis}

Data extracted from each study is presented in Table 1, which includes: authors, country and year; aims(s) or objectives of the study; details of the participants which include total number of participants ( $\mathrm{n}=$ brothers and sisters), age range or mean \pm standard deviation (SD), ethnicity of the participants, affiliations of the participants where the sample has been selected, details on living with the unaffected siblings; details of the patients, which include total number of ill siblings ( $\mathrm{n}=$ affected brothers and sisters); age range or mean $\pm \mathrm{SD}$ of affected siblings, diagnosis of affected siblings, and duration of the illness. Table 1 also consisted of materials and methods adopted in the study; study findings in terms needs; and major limitations of the study. Table 2 presents the types of major psychosocial needs across seven studies. The focus of this systematic review was on the psychosocial needs of SOPP, hence the findings of the other outcome variables of the respective studies were not considered for the analysis. 


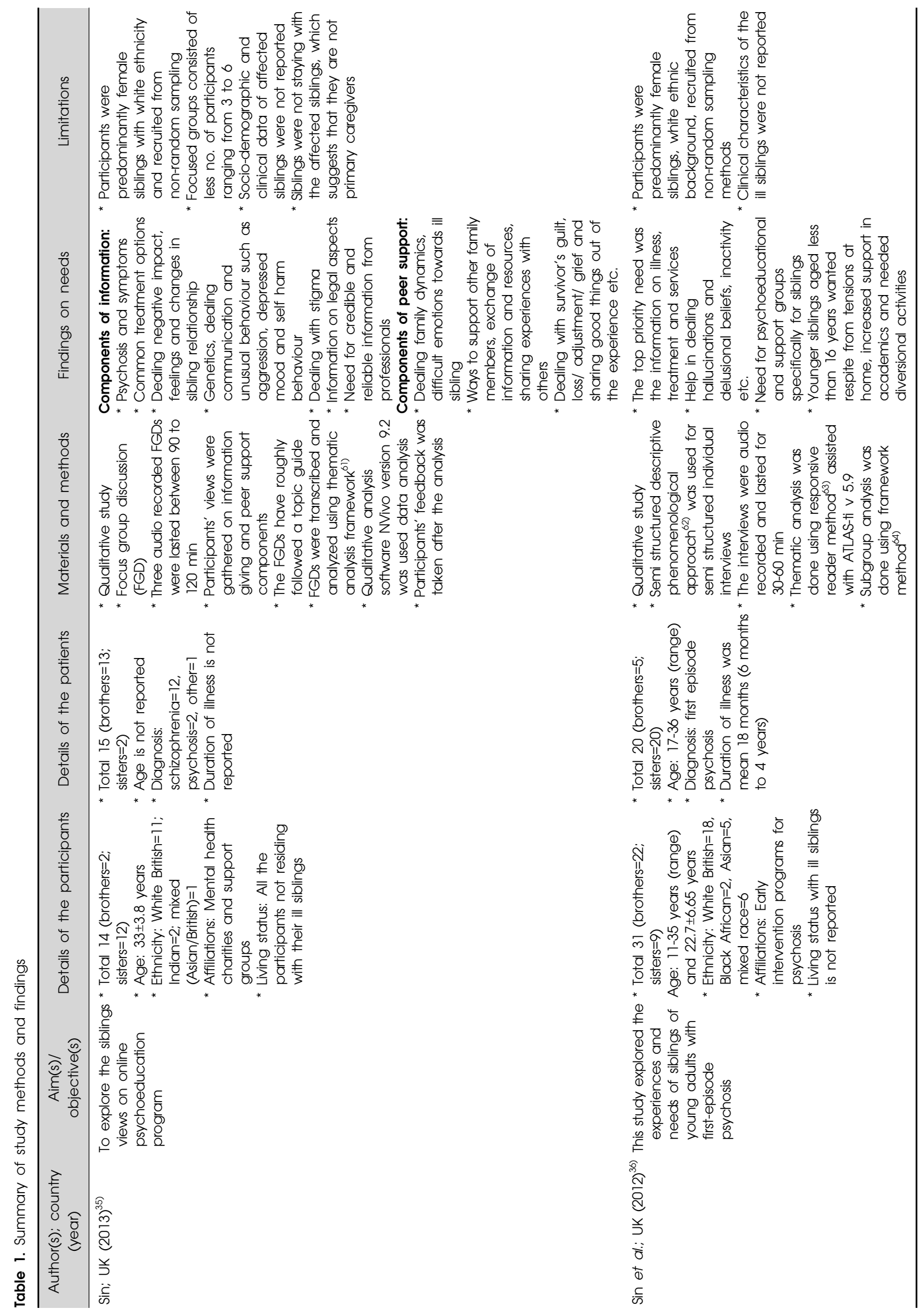




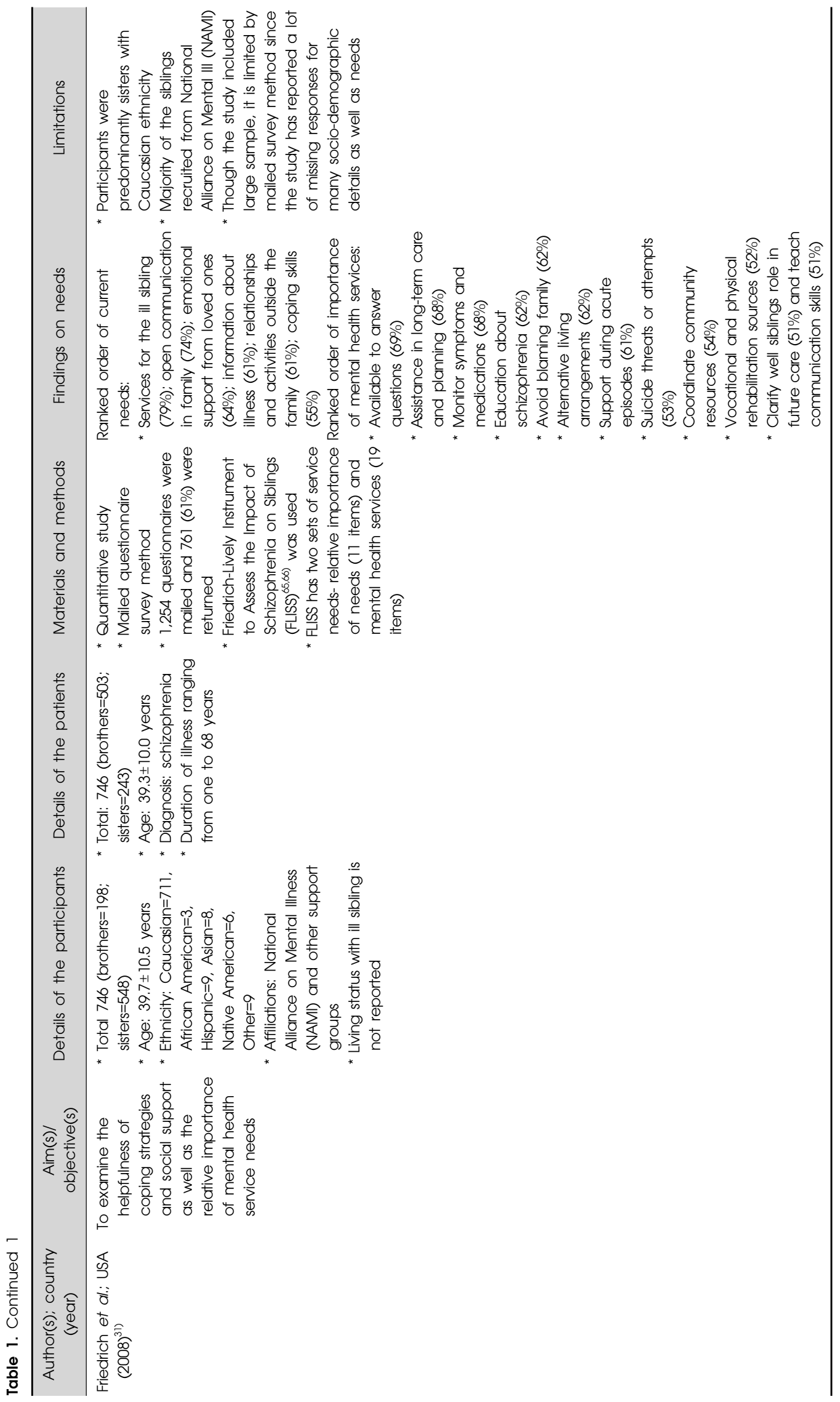




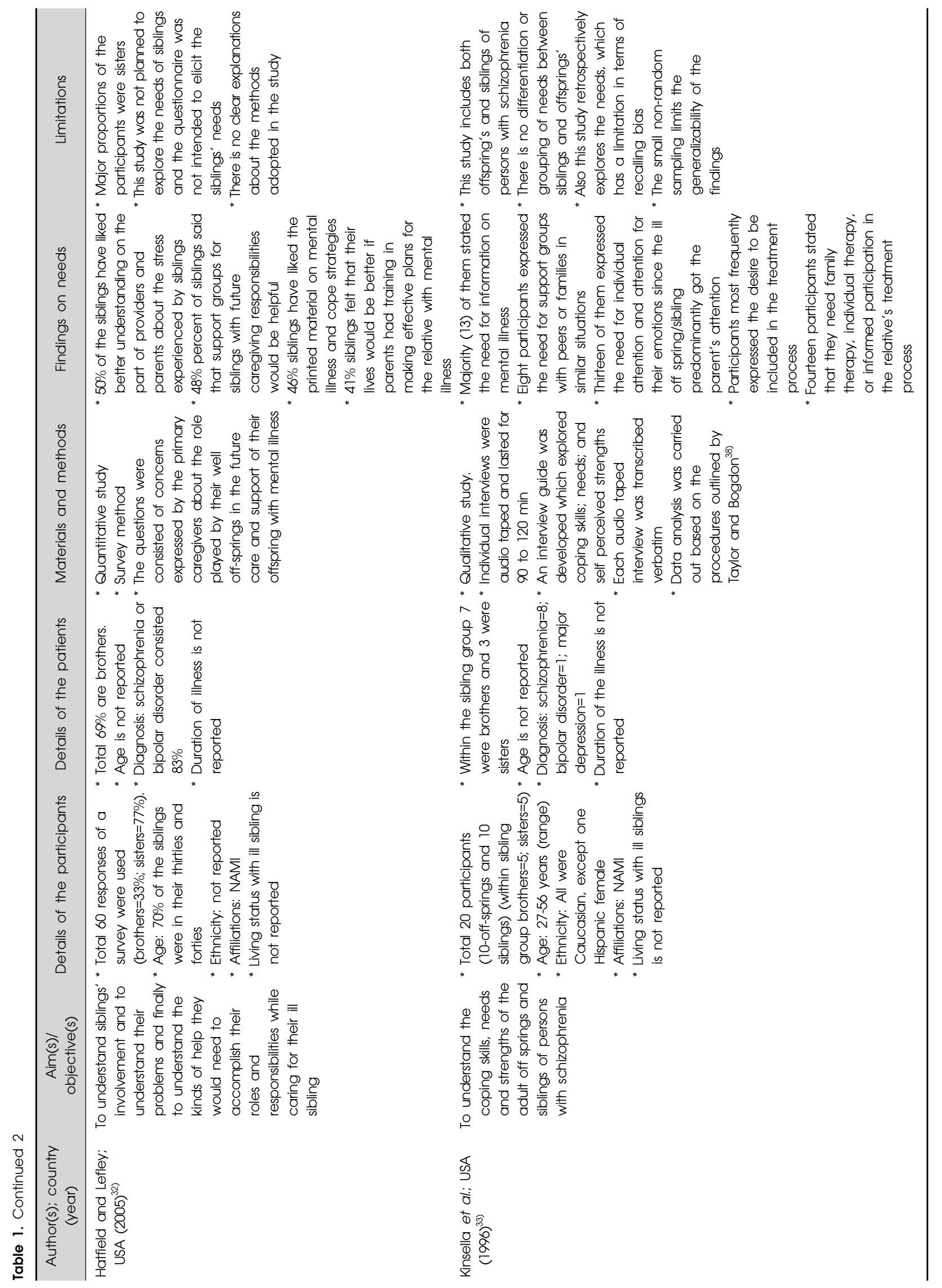




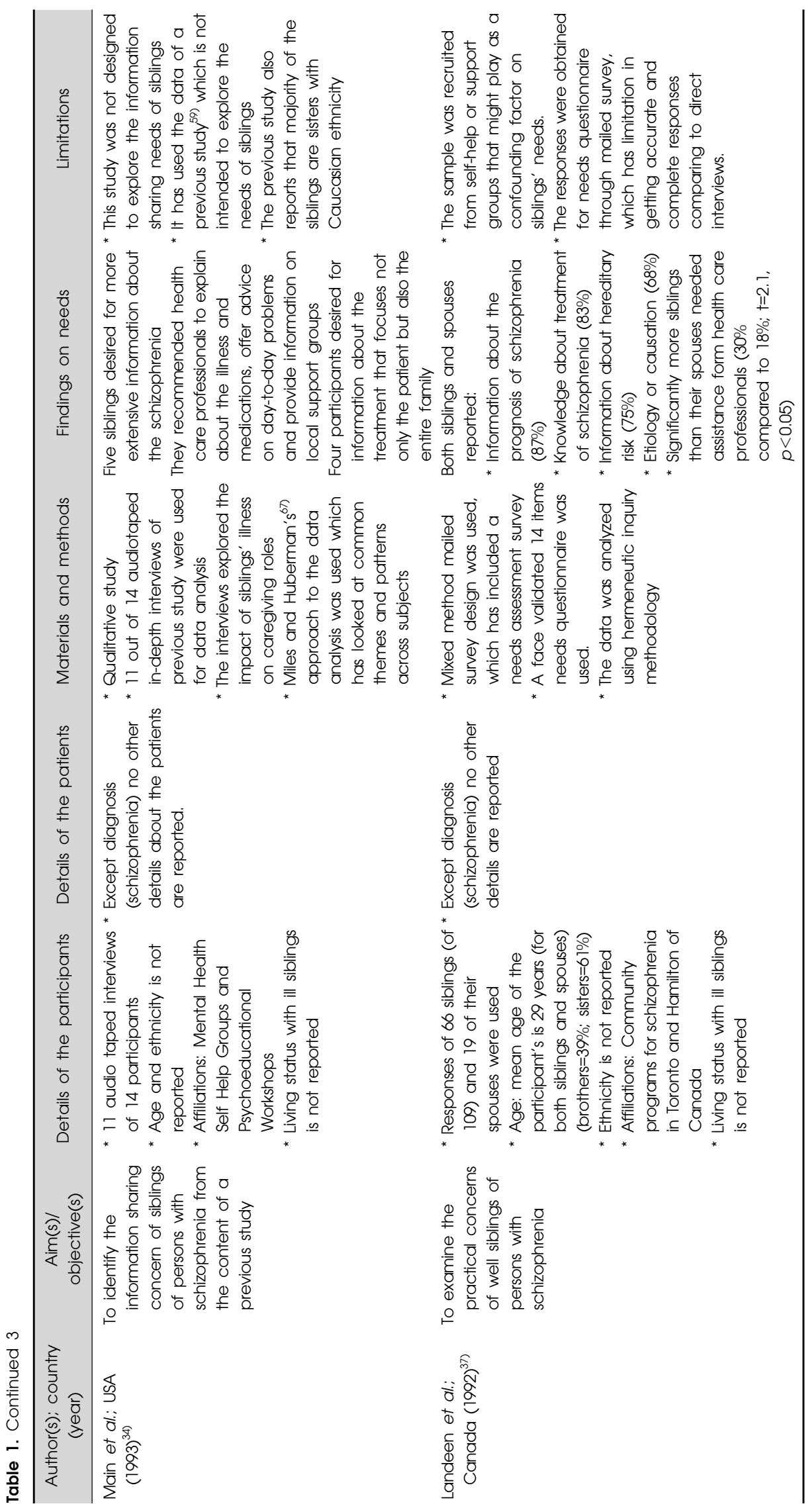


Table 2. Typology of the psychosocial needs of siblings of persons with psychosis (SOPP)

\begin{tabular}{|c|c|c|}
\hline Major theme & Sub themes & $\begin{array}{l}\text { References for } \\
\text { sub themes }\end{array}$ \\
\hline \multirow[t]{6}{*}{ Sibling's informational need } & Information on psychosis or schizophrenia or mental illness and symptoms & $31,33-37$ \\
\hline & Information on prognosis of schizophrenia and etiology or causation & 35,37 \\
\hline & Information about genetics or hereditary risk & 35,37 \\
\hline & $\begin{array}{l}\text { Available to answer questions, information on vocational and physical rehabilitation } \\
\text { sources }\end{array}$ & 31 \\
\hline & Printed material on mental illness and coping & 32 \\
\hline & Information on legal aspects & 35 \\
\hline \multirow[t]{3}{*}{ Need for support groups } & Support groups specifically for siblings & 32,36 \\
\hline & $\begin{array}{l}\text { Support groups with peers and family members in similar situations for support, } \\
\text { exchange of information and resources }\end{array}$ & 33,35 \\
\hline & Information on local support groups & 34 \\
\hline \multirow{6}{*}{$\begin{array}{l}\text { Illness management or } \\
\text { rehabilitation related needs }\end{array}$} & Dealing with hallucinations, delusions and inactivity & 36 \\
\hline & Dealing with self harm, suicidal threats and attempts & 31,35 \\
\hline & Dealing with unusual behaviour such as aggression and depressed mood & 35 \\
\hline & $\begin{array}{l}\text { Assistance in long term care and planning, monitoring symptoms and medications, } \\
\text { coping skills for ill siblings, support during acute episodes, alternative living } \\
\text { arrangements, and coordinating community sources }\end{array}$ & 31 \\
\hline & $\begin{array}{l}\text { Siblings felt that their lives would be better if parents had training in making effective } \\
\text { plans for the relative with mental illness }\end{array}$ & 32 \\
\hline & Advice on daily living problems & 34 \\
\hline \multirow[t]{5}{*}{$\begin{array}{l}\text { Need for help in managing own } \\
\text { psychosocial issues }\end{array}$} & $\begin{array}{l}\text { Dealing negative impact on their own feelings, relationships with siblings, stigma, } \\
\text { family dynamics, negative emotions towards siblings, guilt, loss, grief etc. }\end{array}$ & 35 \\
\hline & $\begin{array}{l}\text { Emotional support from close relatives, younger siblings wanted respite from tensions } \\
\text { at home, increased support in academics and needed recreational activities. }\end{array}$ & 36 \\
\hline & $\begin{array}{l}\text { Need open communication in the family, social relationships and activities, } \\
\text { professionals avoid blaming families; clarify their role in future care of the ill siblings. }\end{array}$ & 31 \\
\hline & $\begin{array}{l}\text { Siblings needed better understanding from the professionals and parents about the } \\
\text { stress experienced by them. }\end{array}$ & 32 \\
\hline & $\begin{array}{l}\text { Need for individual attention from parents since well siblings were ignored because } \\
\text { of the care of affected member was dominated in the family. }\end{array}$ & 33 \\
\hline \multirow{2}{*}{$\begin{array}{l}\text { Treatment related informational } \\
\text { needs }\end{array}$} & Information on treatment of schizophrenia or psychosis & $35-37$ \\
\hline & Explanation about medication & 34 \\
\hline Inclusion in the treatment process & $\begin{array}{l}\text { Participants most frequently expressed the desire to be included in the treatment } \\
\text { process. Fourteen participants stated that they need family therapy, individual } \\
\text { therapy, or informed participation in the relative's treatment process. }\end{array}$ & 33 \\
\hline
\end{tabular}

\section{RESULTS}

We present the results of the seven articles in tables, under two headings: (1) summary of study methods and findings; and (2) typology of the psychosocial needs of SOPP.

\section{Study and Sample Characteristics}

Four studies out of seven were from the USA ${ }^{31-34)}$; two studies from $\mathrm{UK}^{35,36)}$; and one was from Canada. ${ }^{37)}$ The participant's age in these seven studies was between 11 years to 56 years. One study did not report the age of the participants. ${ }^{34)}$ Regarding the sex/relationship of the participants, majority of them were related as sisters of the ill sibling. Caucasian or White British ethnicity was reported by four studies ${ }^{31,33,35,36)}$ while the rest ${ }^{32,34,37)}$ did not report the same.

The siblings were selected through self-help or support groups. Three studies predominantly selected the subjects through the National Alliance on Mentally Ill (NAMI) ${ }^{31-33)}$ while the rest selected them from community mental health service programs, other self help groups and psychoeducational workshops. ${ }^{34-37)}$ Apart from one study ${ }^{35)}$ all other studies did not present data on whether the siblings were staying with their affected siblings during the time at which the studies were being conducted.

Most of the affected siblings were brothers and the age was reported by only 2 studies. ${ }^{31,36)}$ The major group of diagnosis in these studies was schizophrenia and psychosis. The duration of the illness was reported by only two studies ranging from 6 months to 68 years. ${ }^{31,36)}$

\section{Study Characteristics}

Four studies ${ }^{33-36)}$ in this review predominantly used qualitative research design and two studies used quantitative methods ${ }^{31,32)}$ while one study used the mixed method design. ${ }^{37)}$ Regarding data collection methods, three stud- 
ies have used individual interviews ${ }^{33,34,36)}$ while two studies used mailed survey method ${ }^{31,37)}$ and one each using the Focus Group Discussion (FGD) ${ }^{35)}$ and survey method. ${ }^{32)}$ The duration of individual interviews and FGD ranged from $30 \mathrm{~min}$ to $120 \mathrm{~min}$ and it was reported by three studies. ${ }^{33,35,36)}$ Four out of five qualitative studies used audio recording for the data acquisition. ${ }^{33-36)}$ Three studies used semi structured or topic guide for collecting the data, ${ }^{33-35)}$ two studies used questionnaires which included the needs of SOPP, ${ }^{31,37)}$ one study used the descriptive phenomenological approach to understand the subjective experiences and needs of $\mathrm{SOPP}^{36)}$ while another study used a brief questionnaire which primarily highlighted issues related to siblings' expectations and attitudes about future care giving of ill siblings which was able to get a few siblings needs. ${ }^{32)}$ Regarding data analysis three qualitative studies used thematic analysis for analyzing da$\mathrm{ta}^{34-36)}$; one study used hermeneutic methodology ${ }^{37)}$ and another study ${ }^{33)}$ used Taylor and Bogdan's ${ }^{38)}$ procedures for qualitative data analysis. Apart from these qualitative methods two studies have used quantitative data analysis methods. ${ }^{31,32)}$

\section{Findings on Needs of SOPP}

This review showed that six studies out of seven highlighted the need for more information on illness and symptoms. ${ }^{31,33-37)}$ Those were the top priority needs expressed by the SOPP across the studies. The information on prognosis, etiology, genetic or hereditary risk etc. was some of the inconsistent needs expressed by the SOPP across the studies.

The second most desired need of SOPP was participation in support groups. ${ }^{32-37)}$ Two studies have reported that siblings need support groups that specifically include only siblings. $^{32,36)}$

Five out of seven studies reported the need for help in managing their own psychosocial issues. ${ }^{31-33,35,36)}$ These studies reported that siblings required help from professionals and close relatives in managing negative impact on their emotions, relationship issues with siblings, family issues, stigma, social activities, younger siblings wanted individual attention, respite and support in their academics etc.

Five out of seven studies reported needs related to illness management and rehabilitation ${ }^{31,32,34-36)}$ which included dealing with and monitoring psychotic symptoms, inactivity, and medications; aggression, depressed mood, self harm and suicidal behaviour; assistance in long term care, support during acute episodes; living arrangements; getting community resources; advice on daily living problems etc.

Four studies reported the need for treatment related information. ${ }^{34-37)}$ One study observed that the siblings desired for inclusion in the treatment process of ill sibling such as family and individual therapy. ${ }^{33)}$

\section{DISCUSSION}

The primary outcome of this review was to identify the psychosocial needs of SOPP since it will help us to understand their needs and discuss the lacunae in existing literature. Understanding the needs of SOPP is important to provide interventions, since majority of the caregiver research in psychosis has addressed the issues of parents and spouses. The sibling's role in the long term care of the affected sibling is very important since they can provide the much-needed support. In order to involve them in the treatment process clinicians needs to address their issues and identify their needs to provide the necessary interventions. Hence this systematic review discussed the findings of psychosocial needs of SOPP on six major themes that emerged from literature such as informational needs; need for support groups; treatment related informational needs; illness management or rehabilitation related needs; need for help in managing their own psychosocial issues; and inclusion in the treatment process.

The primary systematic search in PubMed database and cross references from other databases yielded only seven studies (4 qualitative; 2 quantitative and 1 mixed method study), which have reported the psychosocial needs of SOPP. The results of this current review substantiate that like parents and spouses of psychosis, SOPP have specific needs. The review provides further evidence that psychosis has a significant impact on the other healthy or unaffected siblings, and they recognize a need for help in various issues. Twenty-three sub themes of six main themes were identified from the findings of seven studies included in this review.

\section{Psychosocial Needs of SOPP}

The review has identified that SOPP have common needs in terms of information on their sibling's illness and symptoms, which corroborates with the results of few studies from China on caregivers of schizophrenia in general. ${ }^{39,40)}$ However the types of educational needs are different among the caregivers, which were information on early warning signs and relapse of illness, side effects of the medications, strategies for solving problems, ways 
of coping with anger, violence and assaulting behaviour and hallucinations, effective ways of coping with stress etc. The educational needs were contrasted with a qualitative study from India on psychosocial needs of caregivers of schizophrenia, where hierarchical needs of the caregivers showed that they desired for help in managing illness behaviour, managing social vocational problems, help in managing their emotional problems, education about illness etc. ${ }^{41)}$ These illness management needs follows the informational and support group needs in the hierarchy of this review.

Another important aspect highlighted through this review was the need for support groups, which was reported by five studies. Two studies cited specific support groups for SOPP. ${ }^{32,36)}$ Rest of the studies reported that they wanted support groups with peers and family members for mutual help and information sharing. ${ }^{33-35)}$ Support groups can fulfill the needs of the siblings and alleviate their issues in caring for a sibling with psychosis. Empirical results show that such groups on caregivers of psychosis were found to be effective in addressing various issues and needs. ${ }^{42-46)}$

Illness management or rehabilitation related needs was reported by five studies. ${ }^{31,32,34-36)} \mathrm{A}$ few previous studies reported that managing illness behaviour was the top priority for the primary caregivers of schizophrenia. ${ }^{41,47)}$ However, most often the siblings do not consider themselves as primary caregivers for their ill siblings. ${ }^{36)}$ This differentiates the priority of needs between the siblings and other primary caregivers. Future studies can focus on differentiating the needs between siblings and other primary caregivers such as parents and spouses, which can direct health care providers in personalizing the interventions.

This review found that SOPP need help in managing their own psychosocial issues across five studies. ${ }^{31-33,35,36)}$ Wide range of needs was found in this theme, consisting of dealing with negative emotions, family issues and negative attitudes towards ill sibling. Siblings felt they wanted support from professionals and parents to deal with the negative impact of the illness. Younger siblings felt they needed individual attention and support in their academics and respite from home. Siblings also needed social relationships and activities outside the family. This shows that siblings were also negatively impacted by the illness, which was evident from several SOPP studies on negative impact or burden. ${ }^{23,24,27,48-51)}$

\section{Socio-demographics and IIIness Variables}

Regarding socio-demographic information there was a gender disparity among the participants since a major proportion of the siblings who participated in these studies were sisters. Though there are no studies to distinguish the needs of brothers and sisters, however a study on gender aspects of parental caregivers of schizophrenia compares the needs of fathers and mothers, which reports that mothers have higher problems and needs in relation to fathers. ${ }^{52)}$ Therefore, gender differences might be present between SOPP in terms of their needs. The studies of this review are predominantly from USA and UK with white British or Caucasian ethnicity. Hence, the findings of this review are of relevance to these countries with these ethnicities. A study comparing caregiving duties and burden among parents and siblings of persons with mental illness reported that black siblings report more caregiving duties than white siblings but report less caregiver burden. ${ }^{53)}$ Hence, the results of this review might go well with siblings of white British or Caucasian ethnicity than others. A review on caregiver burden in schizophrenia discusses that there is differences in the level of burden and attitudes towards ill relatives, among caregivers of various ethnicities. ${ }^{54)}$ Thus, these ethnic differences might play a significant role in determining the types of needs between SOPP of different ethnicities.

The reviewed studies did not report the living status and duration of illness. Living with a relative of schizophrenia with poor socio-occupational functioning is one of the major predictor of burden. ${ }^{43,55,56)}$ The living status can potentially influence the needs of the siblings since the primary and secondary caregivers might have varying degree of burden because of the time spent for caregiving will vary and also the caregiving roles might interfere in their daily lifestyle. ${ }^{57)}$ The roles and responsibilities carried out by caregivers who are living with or without an ill sibling can determine not only their level of burden and quality of life, but also their needs. One more important observation from this review was that majority of the studies have selected their samples through social support groups such as NAMI and others. Affiliations to support groups potentially mediate some of the psychosocial issues of their members and fulfill some of their needs. ${ }^{42)}$

These socio-demographic limitations warrants for further studies comparing needs of sisters and brothers, from lower and middle income countries, studies including siblings from different ethnic backgrounds, living with ill siblings and with varying degrees of functionality or chronicity of illness and siblings without support group affiliation. 


\section{METHODOLOGICAL LIMITATIONS AND FUTURE IMPLICATIONS}

The systematic review has identified several methodological limitations in the studies included, which made the generalization of the results difficult. The majority, five out of seven studies used qualitative methods with small convenient sample. It has been argued that purposive sampling at initial stage and theoretical samplings at later stages of the qualitative studies has some flexibility in acquiring rich data in qualitative designs. ${ }^{58)}$ From this review it was found that there were no direct needs assessment studies on SOPP. The studies included have also aimed at exploring other issues with needs. Hence, studies exclusively on needs assessment of SOPP are required for further understanding of their needs. There were two studies, which were not planned and intended to study the needs of the SOPP. ${ }^{32,34)}$ Among these one study used a questionnaire which was primarily intended to elicit the future caregiving expectations, anticipated difficulties, and need for help. ${ }^{32)}$ The other study ${ }^{34)}$ used the data of a previous study ${ }^{59)}$ which was designed to explore the siblings perspectives on schizophrenia and their family. Mailed survey method was used by one quantitative ${ }^{31)}$ and another mixed method study. ${ }^{37)}$ These mailed survey designs have limitations in terms of missing responses and non-response rates. ${ }^{60)}$ It was evident in the study with a large sample size ${ }^{31)}$ where the data on many socio-demographics as well as needs were missing. It is further recommended that needs of SOPP should be assessed in terms of met and unmet needs to avoid any duplication at the service provision level. Also future studies should discriminate the needs of siblings who are based on their living status with the affected sibling.

This review has some limitations. The quality check for the included studies was not carried out. This review did not include the unpublished literature such as conference abstract and unpublished theses. The less number of studies on the needs of SOPP and majority of the studies from western countries limited its generalizability of findings to other parts of the world. The reviewers did not contact the authors for missing data. Though the current review has these limitations it has its strengths. It is the first systematic review with regard to SOPP and their needs. The findings of this review contribute to the existing knowledge and address the lacunas or limitations in the literature and give the implications for further research in this area.

In conclusion this review suggests that SOPP have pri- mary needs in terms of specific informational and support group needs, these are different in the priority of other caregivers needs. Active inclusion of the SOPP in the on going treatment of their affected sibling will give scope to clinicians to understand their needs and provide necessary interventions. There is a lack of research in this area from Asian and African countries. Further studies from heterogeneous population in terms of gender, ethnicity, living status and illness variables such as diagnosis, duration of illness, functionality etc. could be considered in the future research to substantiate the current findings.

\section{Acknowledgments}

ACA is supported by Wellcome Trust/DBT India Alliance. The Wellcome Trust/DBT India Alliance Senior Fellowship Grant (500236/Z/11/Z) to GVS supports this work.

\section{REFERENCES}

1. Birchwood M, Todd P, Jackson C. Early intervention in psychosis. The critical period hypothesis. Br J Psychiatry Suppl 1998;172:53-59.

2. Graham C, Arthur A, Howard R. The social functioning of older adults with schizophrenia. Aging Ment Health 2002;6: 149-152.

3. Grant C, Addington J, Addington D, Konnert C. Social functioning in first- and multiepisode schizophrenia. Can J Psychiatry 2001;46:746-749.

4. Marwaha S, Johnson S. Schizophrenia and employment - a review. Soc Psychiatry Psychiatr Epidemiol 2004;39:337349.

5. Kim B, Lee SH, Choi TK, Suh SY, Kim YW, Yook KH, et al. Effectiveness of a combined therapy of long-acting injectable risperidone and psychosocial intervention for relapse prevention in patients with schizophrenia. Clin Psychopharmacol Neurosci 2008;6:31-37.

6. Cresswell CM, Kuipers L, Power MJ. Social networks and support in long-term psychiatric patients. Psychol Med 1992;22:1019-1026.

7. Erickson DH, Beiser M, Iacono WG. Social support predicts 5-year outcome in first-episode schizophrenia. J Abnorm Psychol 1998;107:681-685.

8. Pernice-Duca F. Family network support and mental health recovery. J Marital Fam Ther 2010;36:13-27.

9. Brown S, Birtwistle J. People with schizophrenia and their families. Fifteen-year outcome. Br J Psychiatry 1998;173: 139-144.

10. Perese EF, Wolf M. Combating loneliness among persons with severe mental illness: social network interventions' characteristics, effectiveness, and applicability. Issues Ment Health Nurs 2005;26:591-609.

11. Horwitz AV. Siblings as caregivers for the seriously mentally ill. Milbank Q 1993;71:323-339.

12. Horwitz AV. Predictors of adult sibling social support for the seriously mentally III: an exploratory study. J Fam Issues 1994; 15:272-289.

13. Chien WT, Chan SW, Thompson DR. Effects of a mutual support group for families of Chinese people with schizo- 
phrenia: 18-month follow-up. Br J Psychiatry 2006;189:4149.

14. Chien WT, Wong KF. A family psychoeducation group program for chinese people with schizophrenia in Hong Kong. Psychiatr Serv 2007;58:1003-1006.

15. Pickett-Schenk SA, Cook JA, Steigman P, Lippincott R, Bennett C, Grey DD. Psychological well-being and relationship outcomes in a randomized study of family-led education. Arch Gen Psychiatry 2006;63:1043-1050.

16. Stephens JR, Farhall J, Farnan S, Ratcliff KM. An evaluation of Well Ways, a family education programme for carers of people with a mental illness. Aust N Z J Psychiatry 2011;45:45-53.

17. Szmukler G, Kuipers E, Joyce J, Harris T, Leese M, Maphosa W, et al. An exploratory randomised controlled trial of a support programme for carers of patients with a psychosis. Soc Psychiatry Psychiatr Epidemiol 2003;38:411418.

18. Chien WT. Effectiveness of psychoeducation and mutual support group program for family caregivers of chinese people with schizophrenia. Open Nurs J 2008;2:28-39.

19. Shor R, Birnbaum M. Meeting unmet needs of families of persons with mental illness: evaluation of a family peer support helpline. Community Ment Health J 2012;48:482488.

20. Thara R, Padmavati R, Lakshmi A, Karpagavalli P. Family education in schizophrenia: A comparison of two approaches. Indian J Psychiatry 2005:47:218-221.

21. Nasr T, Kausar R. Psychoeducation and the family burden in schizophrenia: a randomized controlled trial. Ann Gen Psychiatry 2009;8:17.

22. Jeppesen P, Petersen L, Thorup A, Abel MB, Oehlenschlaeger J, Christensen TØ, et al. Integrated treatment of first-episode psychosis: effect of treatment on family burden: OPUS trial. Br J Psychiatry Suppl 2005;48:s85-s90.

23. Friedrich RM, Lively S, Buckwalter KC. Well siblings living with schizophrenia. Impact of associated behaviors. J Psychosoc Nurs Ment Health Serv 1999;37:11-19.

24. Lively S, Friedrich RM, Rubenstein L. The effect of disturbing illness behaviors on siblings of persons with schizophrenia. J Am Psychiatr Nurse Assoc 2004;10:222232.

25. Schmid R, Schielein T, Binder H, Hajak G, Spiessl H. The forgotten caregivers: Siblings of schizophrenic patients. Intl J Psychiatry Clinl Practice 2009;13:326-337.

26. Lohrer SP, Lukens EP, Thorning H. Economic expenditures associated with instrumental caregiving roles of adult siblings of persons with severe mental illness. Community Ment Health J 2007;43:129-151.

27. Barak D, Solomon Z. In the shadow of schizophrenia: a study of siblings' perceptions. Isr J Psychiatry Relat Sci 2005:42:234-241.

28. Bowman S, Alvarez-Jimenez M, Wade D, McGorry P, Howie L. Forgotten family members: the importance of siblings in early psychosis. Early Interv Psychiatry 2013. doi: 10.1111/eip.12068. [Epub ahead of print]

29. Nechmad A, Fennig S, Ternochiano P, Treves I, FennigNaisberg S, Levkovich Y. Siblings of schizophrenic patients--a review. Isr J Psychiatry Relat Sci 2000;37:3-11.

30. Teschinsky U. Living with schizophrenia: the family illness experience. Issues Ment Health Nurs 2000;21:387-396.

31. Friedrich RM, Lively S, Rubenstein LM. Siblings' coping strategies and mental health services: a national study of siblings of persons with schizophrenia. Psychiatr Serv 2008; 59:261-267.
32. Hatfield AB, Lefley HP. Future involvement of siblings in the lives of persons with mental illness. Community Ment Health $J$ 2005;41:327-338.

33. Kinsella KB, Anderson RA, Anderson WT. Coping skills, strengths, and needs as perceived by adult offspring and siblings of people with mental illness: A retrospective study. Psychiatr Rehabil J 1996;20:24-32.

34. Main MC, Gerace LM, Camilleri D. Information sharing concerning schizophrenia in a family member: adult siblings' perspectives. Arch Psychiatr Nurs 1993;7:147-153.

35. Sin J. Focus group study of siblings of individuals with psychosis: views on designing an online psychoeducational resource. J Psychosoc Nurs Ment Health Serv 2013;51:2836.

36. Sin J, Moone N, Harris P, Scully E, Wellman N. Understanding the experiences and service needs of siblings of individuals with first-episode psychosis: a phenomenological study. Early Interv Psychiatry 2012;6:53-59.

37. Landeen J, Whelton C, Dermer S, Cardamone J, MunroeBlum H, Thornton J. Needs of well siblings of persons with schizophrenia. Hosp Community Psychiatry 1992;43:266269.

38. Taylor SJ, Bogdan R. Introduction to qualitative research methods: the search for meanings. New York:John Wiley and Sons; 1984.

39. Chien WT, Kam CW, Lee IF. An assessment of the patients' needs in mental health education. J Adv Nurs 2001;34:304311.

40. Chien WT, Norman I. Educational needs of families caring for Chinese patients with schizophrenia. J Adv Nurs 2003; 44:490-498.

41. Jagannathan A, Thirthalli J, Hamza A, Hariprasad VR, Nagendra HR, Gangadhar BN. A qualitative study on the needs of caregivers of inpatients with schizophrenia in India. Int J Soc Psychiatry 2011;57:180-194.

42. Chien WT, Norman I. The effectiveness and active ingredients of mutual support groups for family caregivers of people with psychotic disorders: a literature review. Int $J$ Nurs Stud 2009;46:1604-1623.

43. Chien WT, Chan SW, Morrissey J. The perceived burden among Chinese family caregivers of people with schizophrenia. J Clin Nurs 2007;16:1151-1161.

44. Magliano L, Marasco C, Fiorillo A, Malangone C, Guarneri M, Maj M; Working Group of the Italian National Study on Families of Persons with Schizophrenia. The impact of professional and social network support on the burden of families of patients with schizophrenia in Italy. Acta Psychiatr Scand 2002;106:291-298.

45. Shihabuddeen TM, Gopinath PS. Group meetings of caretakers of patients with schizophrenia and bipolar mood disorders. Indian J Psychiatry 2005;47:153-156.

46. Chien WT, Chan SW. The effectiveness of mutual support group intervention for Chinese families of people with schizophrenia: a randomised controlled trial with 24-month follow-up. Int J Nurs Stud 2013;50:1326-1340.

47. Yeh LL, Hwu HG, Chen $\mathrm{CH}$, Chen CH, Wu AC. Factors related to perceived needs of primary caregivers of patients with schizophrenia. J Formos Med Assoc 2008;107:644-652.

48. Lively S, Friedrich RM, Buckwalter KC. Sibling perception of schizophrenia: impact on relationships, roles, and health. Issues Ment Health Nurs 1995;16:225-238.

49. Lukens EP, Thorning H, Lohrer SP. How siblings of those with severe mental illness perceive services and support. $J$ Psychiatr Pract 2002;8:354-364.

50. Stålberg G, Ekerwald H, Hultman CM. At issue: siblings of 
patients with schizophrenia: sibling bond, coping patterns, and fear of possible schizophrenia heredity. Schizophr Bull 2004;30:445-458.

51. Greenberg JS, Kim HW, Greenley JR. Factors associated with subjective burden in siblings of adults with severe mental illness. Am J Orthopsychiatry 1997;67:231-241.

52. Wancata J, Freidl M, Krautgartner M, Friedrich F, Matschnig T, Unger A, et al. Gender aspects of parents' needs of schizophrenia patients. Soc Psychiatry Psychiatr Epidemiol 2008;43:968-974.

53. Horwitz AV, Reinhard SC. Ethnic differences in caregiving duties and burdens among parents and siblings of persons with severe mental illnesses. J Health Soc Behav 1995; 36:138-150.

54. Awad AG, Voruganti LN. The burden of schizophrenia on caregivers: a review. Pharmacoeconomics 2008;26:149162.

55. Fan CC, Chen YY. Factors associated with care burden and quality of life among caregivers of the mentally ill in Chinese society. Int J Soc Psychiatry 2011;57:195-206.

56. Adeosun II. Correlates of caregiver burden among family members of patients with schizophrenia in Lagos, Nigeria. Schizophr Res Treatment 2013;2013:353809.

57. Winefield HR, Harvey EJ. Needs of family caregivers in chronic schizophrenia. Schizophr Bull 1994;20:557-566.

58. Coyne IT. Sampling in qualitative research. Purposeful and theoretical sampling; merging or clear boundaries? J Adv Nurs 1997;26:623-630.

59. Gerace LM, Camilleri D, Ayres L. Sibling perspectives on schizophrenia and the family. Schizophr Bull 1993;19:637647.

60. Barrios M, Villarroya A, Borrego Á, Ollé C. Response Rates and Data Quality in Web and Mail Surveys Administered to PhD Holders. Social Sci Comput Rev 2011, 2011;29:208220.

61. Ritchie J, Spencer L, O'Connor W. Carrying out qualitative analysis. In: Ritchie J, Lewis J, editors. Qualitative research practice: A guide for social science students and researchers. London:Sage;2003. p.219-262.

62. Giorgi A. The theory, practice, and evaluation of the phenomenological method as a qualitative research procedure. J Phenomenol Psychol 1997;28:235-260.

63. Porter S. Qualitative analysis. In: Cormack D, editor. The research process in nursing. 4th ed. Oxford:Blackwell Science;2000. p.399-410.

64. Miles MB, Huberman AM. Qualitative data analysis. 2nd ed. Thousand Oaks, CA:Sage;1994.

65. Friedrich RM, Lively S, Rubenstein L, Buckwalter K. The Friedrich-Lively Instrument to Assess the Impact of Schizophrenia on Siblings (FLIISS): Part I--instrument construction. J Nurs Meas 2002;10:219-230.

66. Rubenstein L, Friedrich RM, Lively S, Buckwalter K. The Friedrich-Lively Instrument to Assess the Impact of Schizophrenia on Siblings (FLIISS): Part II--reliability and validity assessment. J Nurs Meas 2002;10:231-248.

67. Miles MB, Huberman AM. Qualitative data analysis: a sourcebook of new methods. Beverly Hills, CA:Sage Publications; 1984. 